\title{
Nanotechnology Innovations in Construction Industry and Environmental Sustainability
}

\author{
Ujwal Prabhakar Nandekar, Rupal Rautdesai
}

\begin{abstract}
Nanotechnology is a speedily increasing and innovating range of research, where advanced characteristics of resources manufactures on the nanoscale can be exploited as advantages for people at large through various methods or mechanisms of construction. Being a varied technical and scientific arena that brings and covers numerous application kinds, the contribution of nanotechnological innovations is immense for various sectors of construction industries. It also possesses a large future potential for ecological efficiency, which is dire need of the hour. In construction industry there are many factors involved to achieve the major goal of sustainability like smart design, planning through which energy can be saved, resource usage can be reduced and environmental damage can be avoided.

No doubt, the application of nanotechnology materials and its various causes on the atmosphere and living organisms are not clearly defined yet which can become a problem. For instance, leakage of materials into the water resources, and seas, as well, discharge of nanoparticles into the air generating dust and exposure to harmful materials during various construction, maintenance and use etc. Considering tremendous revolution in Nanotechnological field there is an important aspect in relation to the impact of nanoparticles and nanomaterials on human health and environment which should be discussed at length. This paper intends to give a research review of current and near future, safety and eco-efficiency applications of nanotechnology to not only improve and maintain but also deal with certain future challenges and directions related to the sustainable development.
\end{abstract}

Keywords- Construction industry, concrete, environment, nanostructures, nanotechnology, sustainability.

\section{INTRODUCTION}

In today's scenario, construction industry is one of the biggest contributors to the environmental problems. And sustainability is need of the hour which is directly or indirectly related to developing technological arena. Nanotechnology is known to people at large contributing heavily to construction industry through its various applications and materials. There are hazardous discharges that are outcome of construction industry for instance Sulphur dioxide which is result of energy generation from fossil fuels and fine particles because of extraction of mineral raw materials for construction (Ayşin Sev, Meltem Ezel, 2014). Various research and opinions gathered in US and UK prove that nanotechnology has impacted many industries in positive manner and construction industry is not an exception to it. Furthermore the maintenance costs of

\footnotetext{
Revised Manuscript Received on September 10, 2019.

Ujwal Prabhakar Nandekar, Symbiosis Law School, Pune, Symbiosis International (Deemed University), Pune, Maharastra, India.

(Email: ujwal.nandekar@symlaw.ac.in)

Rupal Rautdesai, Symbiosis Law School, Pune, Symbiosis International (Deemed University), Pune, Maharastra, India.

(Email: rupal@symlaw.ac.in)
}

the industry have drastically reduced because of Nanotechnological exceptional characteristics of selfcleaning, self-repairing mechanisms in construction. (N. Venkat Rao, M. Rajasekhar, K. Vijayalakshmi, M. Vamshykrishna 2014).

In the field of construction industry, nanomaterials are used considering their unique characteristics in order to enhance energy and resource efficiency, and nanomaterials can substitute environmentally hazardous subject matter in certain fields of application discussed in the paper. Considering beneficial aspects of nanotechnology, a specific research was conducted by a scientist at Rice University which emphasized prospective detrimental facets of nanomaterials into the atmosphere (Jaesang Lee, Shaily Mahendra, Pedro J. J. Alvarez, 2010). General observation in regard to the impact of construction industry on environment has been the following:

$\begin{aligned} \text { i. } & \text { release of dangerous air in atmosphere } \\ \text { ii. } & \text { maximum use of natural resources } \\ \text { iii. } & \text { release of impure water in rivers } \\ \text { iv. } & \text { contamination of soil } \\ \text { v. } & \text { other related issues of pollution } \\ \text { vi. } & \text { conveyance issues } \\ \text { vii. } & \text { various environmental disasters/ accidents } \\ \text { viii. } & \text { affecting biodiversity }\end{aligned}$

So, the question is whether the above issues can be tackled with the help of nanotechnology innovations? Are we going to get some assistance from nanotechnology related advancements to deal with environmental sustainability? There are number of questions which can be raised to address the serious issue of sustainability because it is global environmental threat and directly related to 'Our Common Future' (Brundtland Commission Report, 1987). The scope and ambit of sustainable development is much wider than what we think of, it's about meeting needs of different people from different communities from any corner of globe, social unity and equality, healthy and better ways of doing things without affecting the quality of life (Observatory Nano, 2009). Sustainable development can be easily understood as the balance between production and consumption so as to target the requirements of not only existing population but also upcoming one.

\section{METHODOLOGY}

This research paper follows literature review approach of research wherein the literature is gathered from various interdisciplinary fields such as science, environment, law 
and economics which is then holistically analysed to provide conclusions, suggestions and further scope of research. Initially, doctrinal research informs the foundations of the basic concepts in the research paper. Further various research papers, journal articles, governmental reports referred by the researchers bring out the benefits and future aspects of nanotechnology in construction industry. Researchers have further examined the aspect of use of nanotechnology and its numerous applications which contribute to sustainable development. Further researchers have undertaken critical analysis of past, present and future scenario of nanotechnology in construction industry to provide valuable suggestions to set a way forward.

\section{DISCUSSION \& RESULTS}

An empirical research in Iran shows the wider ambit of nanotechnology in construction industry which has not only tried to achieve developmental plans but also managed the energy consumption with nanomaterials to go forward near sustainability and improving the way of life, pave the way for next generation (Fariborz Haji Seyed Javadi, Raziyeh Zeynali, Farzaneh Shahsavari and Zahra Motevali Alamouti, 2015). When we talk about nanotechnology applications in construction industry some of the important aspects are protection. There are many more aspects however; the researchers choose to limit the scope of the research paper to the aforementioned aspects, which are discussed below in detail.

\section{Nanotechnology in Concrete and Cement}

The very basic nature of concrete is a heterogeneous, very small in structure, multi-phase, small crystals etc. Entire construction site is incomplete without it. It is having so much importance as it occupies around $70 \%$ of the entire volume of structure. Again, another aspect is cement which is responsible element for preparing concrete, and it has many shortcomings. Research has laid down some disastrous outcomes which talks volumes about the disadvantages of cement (Zahra Azizi Shirkoohi, 2016). And nanotechnology has provided the best way to answer numerous problems associated with important constituents of concrete. The characteristics of concrete can be altered through various modes by using nano particles. For instance, nanoparticles with reference to silica, nano clays, nano titanium oxide ( $\mathrm{TiO} 2)$, nano iron (Fe2O3), nano alumina (AI2O3), $\mathrm{CuO}, \mathrm{ZnO} 2$ and $\mathrm{ZrO} 2$ (Kurapati Srinivas, 2014). Very important properties of concrete such as strength, ductility, hardness and durability can be increased with the help of nano materials. There are basically two factors involved in this process, at very early stage there is a problem in terms of durability of concrete because of addition of fly ash which is responsible to add strength to the concrete in later stages. The raised issue at early stage can be addressed by adding silicon dioxide nano particles which provides the compactness and assembly of the concrete. Similarly, nano iron and nano titanium can help and improve the capability of self-sensing, compressive, flexural strength and self-cleaning respectively.

The empirical research piloted by National Institute of Standards and Technology, US treated the concrete with cement, concrete, steel, paint coating, glass and fire

nanomaterials in viscosity modifiers which improved and appreciate the lifetime of bridges. This research successfully tackled the wear and tear of bridges which mainly was caused due to environmental elements including chloride and sulfate ions (D.P. Bentz, M.A. Peltz, K.A. Snyder and J.M. Davis, 2009). One more research conducted by the University of Illinois, Urbana came up with micro capsule as curative means and catalytic substance. In the said process microcapsules would be fragmented by concrete fissures and a healing agent would be released into the crack and get in touch with the catalytic chemical agent (Henghua Jin, Chris L. Mangun, Dylan S. Stradley, Jeffrey S. Moore, Nancy R. Sottos, Scott R. White, 2012). Decaying structure is one of the other troublesome areas for engineers, and fiber wrapping having nano silica particles and hardeners plays vital role in it. Apart from decaying structures, nano silica also helps in closing the split on the outside part of concrete which is a common situation now-a-days. Therefore, it is understood that nanotechnology is providing tremendous scope to overcome the issues raised by the traditional techniques of concrete and its usage in construction industry and maintain environmental sustainability.

\section{Nanotechnology and Steel}

During the years steel has been considered as one of the important and absolutely necessary subject matter in the construction industry. However, one of the limitations that prevail is fatigue, which is one of the major issues. It has been successfully answered by the nanotechnology innovations by introducing copper nano particles. It provides a smoother and even surface of steel and evenness may decrease the tensions which directly address the fatigue cracking. Corrosion resistance along with light weight is one of the important factors which can be easily traced in new generation steel. Recently, MFX steel corporation USA has developed modified steel which uses nanostructures., Its main characteristics are higher strength, ductility and fatigue resistance as compared to traditional steel (S. Praveen, S. Rajesh and S. Akhil, 2016). These mechanisms generally provide larger and higher durability of construction even in adverse climatic and corrosive environment. Thus nanotechnology can be very beneficial when it comes to creating or maintaining environmentally sustainable development. Nanomaterials show exceptional physical and chemical properties that make the subject matter interesting for innovation and environmentally welcoming structures.

\section{Nanotechnology and Glass}

Now-a-days various cutting-edge inventions related to glass are giving different options to the user to explore technological advances. Usage of such glass in extremely mixed sectors of industry like energy, medicines, gadgets, electronics and communications are essentially something out of the box. Integrating nano-materials into glass mediums permits the manufacturer of windows with the competence to regulate the mechanism of how light and heat pass through building walls. Nanotechnological applications may provide some options for construction industries

Published By:

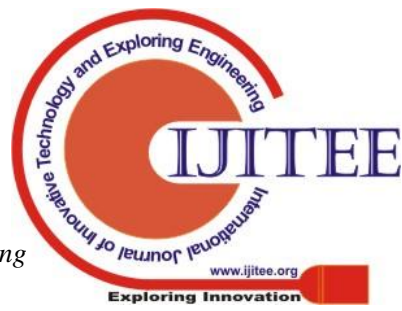


through energy conservation by reducing heat loss. For example: usage of nano manufactured low emissivity glass, reducing energy consumption for ventilation and air conditioning by restricting solar heat through the usage of solar control and heat absorbing glass.

\section{Nanotechnology and fire protection mechanism}

Nano-clay which is nano structured silicate particles is specifically mixed in plastic material to optimize its noninflammable characteristics and heat resistance. Such nano materials or nano-composites play very important role in cable insulations and manufacture of covers for circuits, fuse boxes, electrical sockets, and appliances. Nano material (thin and light panes) such as Silicon dioxide has capacity to withstand a continuous fire of more than $1832 \mathrm{~F}\left(1000^{\circ} \mathrm{C} \times\right.$ $9 / 5)+32=1832^{\circ} \mathrm{F}$ ) for more than 2 hours.

\section{Nanotechnology in energy savings}

Again, one of the major challenges in construction industry is thermal renovation of various buildings. The insulation made with the help of nano materials may address this challenge wherein energy savings can be done. With the help of nano materials, the Austrian Energy efficiency Action Plan has introduced the EU Energy Efficiency and Energy Services Directive which claimed saving of around 9\% of the annual average energy consumption (Fawcett, T., Rosenow, J. \& Bertoldi, 2018). With increasing characteristics and development of LED \& OLED machinery and development in the cloistering ingredients and intelligent finishing, the apparition for prerequisite will become a certainty.

\section{Positive impact and challenges of nanotechnology}

Nanotechnology has always given exploratory scope for new developments. Nanotechnology has wide range of impact on construction industry in a positive way. For instance, at a yearly manufacture frequency of around 2000 million tons, the cement industry alone contributes almost $5 \%$ to global anthropogenic $\mathrm{CO} 2$ emissions. However, the use of nanotechnological advancements which use extracts such as belite, calcium sulfo-aluminate and calcium alumino-ferrite have been found to decrease the $\mathrm{CO} 2$ releases by nearly $25 \%$ in the manufacture phase (Ali Naqi and Jeong Gook Jang, 2019).

Further the market scenario of Carbon nano tubes is on the way of continuous progress. There is huge reduction in construction time and decrease in not only number of laborers but also cost of repair and maintenance. Nano alumina and titania provide double durability and bond strength. There will be a rapid increase in nano composites in near future. There will be a rapid increase in demand of fire protection system from $\$ 45$ billion to more than $\$ 80$ billion. A tremendous advantage for nanoparticles which is having capacity to repair itself the harmed structures leads to an innovative approach of construction industry. In addition to it, the unique characteristics of fixed or inserted nano sensors in certain structures or resources and materials can provide maximum benefit at very low or reasonable costs. Similarly, other mechanisms like senses to failures in constructions, detecting defects in materials and foreseen the benefits involved in the resources may provide wonderful structures to come across their own energy

outcomes associated with it e.g. structures related to water plants, energy related hazardous constructions etc.

The advantages and positive impact of nanotechnology in the construction industry are very vast in nature. The most important advantage of applying nanotechnology to conventional construction materials is the fact that such materials can be modeled with expected characteristics that will modify to get maximum output and which will also help achieve sustainable construction practice. Sustainable construction practices differ from society to society. Those are basically environment friendly which enhance the local flora and fauna reducing pollution and combination of renewable sources of energy by using operative and wellorganized resources. It may include smart methods of designing various construction models, use of sustainable products, harvesting rain water and using it for construction.

Some of the challenges are that small production volumes at high cost continue to be a hurdle to the use of nanotechnology. Further the duration for taking the nanotechnological product in the market and commercializing is long. For example, the material which has characteristics to replace or exclude the usage of steel bars inside the construction will probably visit the construction market by 2 to 3 years from now.

The most significant concern connected to nanotechnology is not only with respect to human health but also environment and ecology which is having very hazardous effect on society and day to day livelihood of people at large. It has had a negative impact through various modes though there are technological advancements and advantages at the same time. Research has shown that government is very slack in forming a controlling body to anticipate the harmless development and commercialization of nanotechnology innovations (Amit Kumar, 2014).

Considering the very nature of nano particles there is a maximum possibility that it will not only affect the important aspects in vivo but also ex vivo of living organisms and ecology. The recent empirical researches show that nano particles which are breathed in accidentally or deliberately cannot be cleaned or purified or removed by the white blood cells as compare to larger particles. And there is a high propensity of these nanoparticles to travel throughout body of living organisms via different modes which may affect the highly complex nerve cells and fibers.

Construction workers are usually less educated and do not possess the appropriate knowledge or experience to handle construction material inclusive of nano subject matter. Mandatory training of the construction workers could be a possible solution. However, in India where large number of construction workers are found not even wearing the basic safety gadgets used in construction industry, the ideal of training on handling nanotechnological materials looks to be farfetched though not impossible. There is lack of appropriate policies governing the $\mathrm{R} \& \mathrm{D}$, manufacture, sale and usage of nanotechnology in the construction industry.

There are number of various regulations by European Union which has mention of nanomaterials which deal with

Published By: 
definition, approval procedure, safety assessment and labeling guidance, but there are no provisions which will deal with punitive measures in case of harm (Rauscher et. al. 2017). Regulation (EC) No 1907/2006 related to Registration, Evaluation, Authorization and Restriction of Chemicals (REACH's) main objective is to address implementation issues related to regulatory framework for marketing and use of nanomaterials. It provides strength to existing EU frameworks which are dealing with nanomaterials. Along with it, regulation also focuses on protecting environment from nanomaterials. The regulation also obligates member states to include penalties for noncompliance with the regulation.

\section{CONCLUSION AND SUGGESTIONS}

Unique characteristics associated with nano materials always have the capacity to prepare products or processes suitable to environment. Construction industry is taking out maximum benefit out of nanotechnology wherein new characteristics of materials are manufactured on the nanoscale. Carbon nanotubes, Silicon dioxide nanoparticles, Titanium dioxide nanoparticles, Iron oxide nanoparticles, Copper nanoparticles, Silver nanoparticles and Quantum dots are playing important role in not only encouraging revolution in the field of construction but also maintaining sustainable environmental development.

Research has proven that with the help of nanotechnology we can improve the environmental quality of building. It is pertinent to note that various encouraging advancements prevail which can actually not only reduce the cost but also improve the service life and life cycle of construction infrastructure. Seeing huge benefit of incorporation of nanotechnology in all/ any kind of field, product, processes etc. for developmental purposes may bring challenges/ difficulties related to environment, health, safety risks, ethical and social issues, market adoptability and consumer approach. Understanding that the production of nanomaterials might be ecologically troublesome, and that there are possible negative impacts on living organisms and protection measures related with their manufacture, it is vital for researchers, academicians and scientists to examine the adjustments required by evaluating the forthcoming profits of nano-related materials in contradiction of their unintentional undesirable influences.

Considering Indian legal scenario, there is a need to revisit and modify various legislations, governmental policies and regulations to make it well versed with the Nano technological aspects. Prospects and advantages of complex subject of such advanced technical and scientific field can be addressed with the help of a robust and flexible controlling structure which will answers all the raised issues related to living organisms including preventive measures. Overall cooperation among national and international bodies is required to maintain and lay down a strong and safe mechanism related to nanotechnology. Guidelines and Best Practices for Safe Handling of Nanomaterials in Research Laboratories and Industries released by DST, India is one of the initiative taken by government. The very basic nature of guidelines deals with precautionary measures taken by the user to handle or dispose of nanomaterial in laboratory research and industry. However, this alone is not enough. India may want to consider comprehensive regulations as present within the European Union.

Further Nanomaterials are basically coming under the big umbrella of chemicals and it is now very important to have a regulatory mechanism on it. Some countries have proposed a set of guidelines which may provide certain precautionary approach while dealing with nanomaterials with the help of different modes of using and handling it. But the important question is whether having preventive or cautious approach will take away liability of the responsible person or organization which is dealing with potential hazardous nanomaterials. Another question is whether merely introducing guidelines or preventive measure will address the problem where huge amount of damages have been suffered by people at large? Whether there is a need to have a strong regulatory framework which not only provides for handling safeguards of nanomaterials but will also provide punitive measure for not complying with the measures?

Thus the suggestions of the researchers for Indian Government and lawmaking body are as follows:

- We need an effective risk governance system which will deal with the technological developments comprehensively.

- $\quad$ For safer use of nanomaterials which will have no or minimum hazardous effect on living organisms, ecology and environment, it is important to understand about their sources, interactions and possible risks through thorough research.

- For manufacture and sale of nanotechnological products innovative or otherwise there should be a clearance mechanism through the government, wherein the government must ensure mandatory disclosures in regard to the impact on living organisms and ecology. Government can make submission of impact assessment report mandatory where nanotechnology is used.

- Cooperation between various governmental agencies, research and development departments, manufacturers and other stake holders will be required to frame and implement informed policies in the field of nanotechnology.

- With the help of various international organizations, inter-governmental organization, bilateral and multilateral agreements address the issues related to regulatory framework of nanotechnological innovations.

\section{SCOPE FOR FURTHER RESEARCH}

Many of the world's largest and big construction companies are dealing with high risk and benefit research and development related to nanotechnology. There is a dire need to check through various aspects of research where it is to be confirmed that the advantages expected by nanotechnology can be achieved to deliver maximum benefit and more inexpensive conveyance substructure without prejudice to living organisms and atmosphere. Furthermore, nanotechnology remains under enquiry, whether it can be made justifiable and how it's potential can be assessed and realized. The hazards of nanotechnology on 
living organisms and ecology are scarcely well researched which is another dimension that can be researched. Adopting law and policies to regulate the field of nanotechnology R \& D, manufacture, sale and liability in case of harm caused is another major area of research.

\section{REFERENCES}

1. A. Sev, M. Ezel. (2014, April). Nanotechnology Innovations for the Sustainable Buildings of the Future. World Academy of Science, Engineering and Technology International Journal of Architectural and Environmental Engineering. Volume 8(8), pp.886-896. Available: https://waset.org/publications/9999095/nanotechnologyinnovations-for-the-sustainable-buildings-of-the-future

2. M. F. Leone. (2012, May). Nanotechnology for Architecture. Innovation and Eco-Efficiency of Nanostructured Cement-Based Materials. Journal of Architectural Engineering Technology. Volume 1(1). Available: https://www.omicsonline.org/peerreviewed/nanotechnology-for-architecture-innovationand-ecoefficiency-of-nanostructured-cementbasedmaterialsp-6508.html

3. A. S. Yousef Mohamed. (2015, April). Nano-Innovation in Construction, A New Era of Sustainability. International Conference on Environment and Civil Engineering (ICEACE' 2015) Pattaya (Thailand). pp. 95114 Available: http://iae.org/images/proceedings_pdf/5714IAE0415416.pdf

4. M. Steinfeldt, U. Petschow, R. Haum, A. Gleich. (2004, October). Nanotechnology and Sustainability. Institute for Ecological Economy Research (IOEW), Discussion paper $65 / 04$ of the IOEW Berlin. Available: http://www.sustentabilidad.uai.edu.ar/pdf/tec/dp6504.pdf

5. M. G. Tyshenko. (2010, January). Nanotechnology innovation as a deus ex machine and potential effects on sustainability in a global context. International Journal of Nanotechnology. Volume 7(2/3), pp.209-223. Available: https://www.researchgate.net/publication/253720217_Na notechnology_innovation_as_a_deus_ex_machine_and_p otential_effects_on_sustainability_in_a_global_context

6. K. Warwick. (2013, August). Beyond Industrial Policy: Emerging Issues and New Trends. OECD Science, Technology and Industry Policy Papers, No. 2, OECD Publishing. http://dx.doi.org/10.1787/5k4869clw0xp-en. Available at https://www.enterprisedevelopment.org/wp-

content/uploads/Beyond_Industrial_Policy.pdf

7. M. E. Jarvie. (1987). Brundtland Report. World Commission on Environment and Development. Available: https://www.britannica.com/topic/BrundtlandReport

8. T. Fleischer, A. Grunwald. (2008, August). Making nanotechnology developments sustainable: A role for technology assessment? Journal of Cleaner Production. Volume 16, pp.889-898. Elsevier. Available: http://www.cpe.vt.edu/globaltechseminars/downloads/Ca seStudy_2_2ReadingMaterial.pdf

9. I. Iavicoli, V. Leso, W. Ricciardi, L. L. Hodson, M. D. Hoover. (2014, October). Opportunities and challenges of nanotechnology in the green economy. Environmental Health. Volume 13. Available: https://ehjournal.biomedcentral.com/articles/10.1186/147 6-069X-13-78

10. N. V. Rao, M. Rajasekhar, K. Vijayalakshmi, M. Vamshykrishna. (2015, June). The Future of Civil Engineering with the Influence and Impact of Nanotechnology on Properties of Materials. Procedia Materials Science. Volume 10, pp.111-115. 2nd International Conference on Nanomaterials and
Technologies,

Elsevier.

Available: https://www.sciencedirect.com/science/article/pii/S22118 12815002709

11. Z. A. Shirkoohi. (2016, March). Application of Nanotechnology in the Concrete Industry Improve the Performance of Sustainable Buildings. International Academic Journal of Science and Engineering International Academic Journal of Science and Engineering. Volume 3(3), pp.89-97. Available: http://iaiest.com/dl/journals/7-

\%20IAJ\%20of\%20Science\%20and\%20Engineering/v3i3-mar2016/paper10.pdf

12. K. Srinivas. (2014, June). Nanomaterials for Concrete Technology. International Journal of Civil, Structural, Environmental and Infrastructure Engineering Research and Development. Volume 4(3), pp. 79-90. Available: http://www.tjprc.org/publishpapers/2-11-1402060100absNANOMATERIALS\%20FOR\%20CONCRETE\%20 TECHNOLOGY.pdf

13. D.P. Bentz, M.A. Peltz, K.A. Snyder, J.M. Davis. (2009, January). VERDICT: Viscosity Enhancers Reducing Diffusion in Concrete Technology. Concrete International. pp.31-36. Available: https://concrete.nist.gov/ bentz/CI3101Bentzreadonly.pd $\mathrm{f}$

14. H. Jin, C. L. Mangun, D. S. Stradley, J. S. Moore, N. R. Sottos, S. R. White. (2012, July). Self-healing thermoset using encapsulated epoxy-amine healing chemistry. Polymer. Volume 53(2), pp. 581-587 Elsevier. Available: http://autonomic.beckman.illinois.edu/nrs120.pdf

15. S. Praveen, S. Rajesh, S. Akhil. (2016, June). A Study on Applications of Nanotechnology in Civil Engineering, The Asian Review of Civil Engineering. Volume 5 (1), pp.36-41. Available: http://www.trp.org.in/wpcontent/uploads/2016/11/TARCE-Vol.5-No.1-Jan-June2016-pp.36-41.pdf

16. J. Lee, S. Mahendra, P. J. J. Alvarez. (2010, July) Nanomaterials in the Construction Industry: A Review of Their Applications and Environmental Health and Safety Considerations. ACS Nano. Available: https://pubs.acs.org/doi/abs/10.1021/nn100866w

17. T. Fawcett, J. Rosenow, P. Bertoldi. (2018, April). Energy Efficiency obligation schemes: their future in the EU. Energy Efficiency. Volume 12(1), pp. 57-71 Available: https://link.springer.com/article/10.1007/s12053-0189657-1

18. A. Oke, C. Aigbavboa, S. Kgothatso. (2017, January) Review of the Application of Nanotechnology for Sustainable Construction Materials. Advances in Engineering Research. Volume 102, pp.364-369 Available:

https://www.researchgate.net/publication/319198828_Re view_of_the_Application_of_Nanotechnology_for_Susta inable Construction_Materials

19. F. H. S. Javadi, R. Zeynali, F. Shahsavari, Z. M Alamouti. (2015, April) Study of Nanotechnology Application in Construction Industry (Case Study: Houses in North of Iran). Current World Environment, Volume 10(1), pp.1138-1144. Available: http://www.cwejournal.org/pdf/vol10noSpecial/CWE_V ol10_Spl(1)_p_1138-1144.pdf

20. A. Naqi, J. G. Jang. (2019, January). Recent Progress in Green Cement Technology Utilizing Low-Carbon Emission Fuels and Raw Materials: A Review. MDPI 
21. Sustainability Journal. Volume 11(2), pp.1-18. Available: https://ideas.repec.org/a/gam/jsusta/v11y2019i2p537d199377.html

22. A. Kumar. (2014, December). Nanotechnology Development in India: An Overview, RIS Discussion Papers. Available: http://ris.org.in/images/RIS_images/pdf/DP\%20193\%20 Amit\%20Kumar.pdf

23. S. Bhattacharya, J. A. Pushkaran, Shilpa. (2012, July). Nanotechnology Development in India: Investigating Ten Years of India's Efforts in Capacity Building. CSIR-NISTADS Strategy Paper I, India. Available: https://nistads.res.in/sites/default/files/nano1_0.pdf

24. Guidelines and Best Practices for Safe Handling of Nanomaterials in Research Laboratories and Industries, (2016) Nano Mission, DST, Govt. of India. Available: http://nanomission.gov.in/What_new/Draft_Guidelines_a nd_Best_Practices.pdf

25. H. Rauscher, K. Rasmussen, B. Sokull-Klüttgen. (2017, February). Regulatory Aspects of Nanomaterials in the EU. Chemie Ingenieur Technik. Volume 89 (3), pp. 224 231.

Available: https://onlinelibrary.wiley.com/doi/pdf/10.1002/cite.2016 $\underline{00076}$

\section{AUTHORS PROFILE}

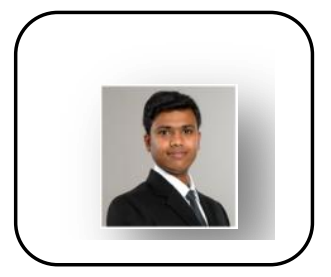

Ujwal Prabhakar Nandekar

BA LL.B, PGDBM, LL.M. PhD (Pursuing)

Ujwal Prabhakar Nandekar has done B.A. LL.B. from RTM Nagpur University's Dr. Babasaheb Ambedkar College of Law (Main Branch), Nagpur in 2010 and LL.M. in Intellectual Property Rights (Law) in 2013 from Symbiosis Law School, Pune, Constituent of Symbiosis International University. Currently, he is pursuing $\mathrm{Ph} . \mathrm{D}$. in Intellectual Property Law from Faculty of Law, Symbiosis International University. He is teaching Law of Torts including Consumer Protection Act and Motor Vehicle Act besides Intellectual Property Laws to under Graduates and Diploma Courses.

His research interest includes Intellectual Property Laws. He has published his dissertation thesis titled as "Critical Evaluation of Copyright Act, 1957 In Light of Copyright (Amendment) Act, 2012" with LAP LAMBERT Academic Publishing in 2013. He has also published journal articles, research papers in SCOPUS indexed journals.

$\mathrm{He}$ is associated with various research projects and has presented papers in various national and international conferences/ seminars with focus on IPRs. He is a member of Editorial Committee of Symbiosis Student Law Review and Symbiosis Contemporary Law Journal at Symbiosis Law School, Pune. He is a Researcher of Intellectual Property Cell, Symbiosis International (Deemed University).

\section{Publications:}

1. BOOK: Nandekar Ujwal (12/2013) Critical Evaluation of Copyright Act, 1957: In Light of Copyright (Amendment) Act, 2012. LAMBERT Academic Publishing (ISBN: 978-3-65950273-6). International

2. Nemane Vivek, Nandekar Ujwal (09/2014) International Court of Justice: Decision Compliance as an Immediate Concern. International Journal of Legal Research, 1(1) : 200-212 ( ISSN: 2349-8463). (National)

3. Nandekar Ujwal (12/2014) Patenting Nanotechnology: Exploring challenges. In: Advances in Biotechnology and Patenting (Edited by: S. Sivaramakrishnan, A. Ilangovan, R. Karthik Raja) Elsevier India Private Limited, pp: 105-116 (ISBN: 9789351073079). (National)

4. Rautdesai Rupal, Nandekar Ujwal (03/2017) Online Photographs in News: Copyright Perspective. Media Watch, 8(1): 133-140 (Scopus; ISSN: 2249-8818). International Scopus

5. Jonnavithula Gayatri Anugha, Ujwal Prabhakar Nandekar (04/2017), Economic Aspiration, Polluted Respiration: Story of Developing India, Environmental Law and Practice Review (ISSN 2319-1856) Volume 5 2016. (National)
6. Rupal Rautdesai, Ujwal Nandekar, Aditya Kedari, Yogesh Patil, $(05 / 2019)$ "Big data and privacy - A legal perspective and comparative study of United States and India" International Journal of Process Management and Benchmarking, ISSN online: 1741-816X ISSN print: 1460-6739 International Journal Scopus Indexed International

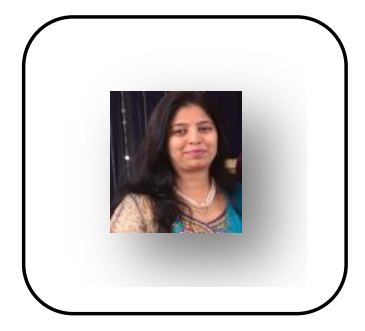

\section{Dr. Rupal Rautdesai}

B.Sc. LL.B. LL.M. PhD. NE

Dr. Rupal Rautdesai graduated in Science after which she found her passion in Law. This led her to get a Bachelor and subsequently a Masters in Law from V. M. Salgaocar College of Law, Miramar, Goa. She has completed her doctorate in Law from Veer Narmad South Gujarat University, Surat and her research was on "Subject Matter of Patent: A comparative study with reference to India United States and United Kingdom". Her area of specialization is Intellectual Property Rights. She is registered as a Patent Agent with the Indian Patent Office.

After obtaining her degree in Law, she practiced as an Advocate for two years and then joined into fulltime teaching since 2005. She has more than 13 years of experience in teaching. She has guided several LL.M. students in the last 10 years. She is also a recognised $\mathrm{PhD}$ supervisor (Guide) and has 6 students pursuing $\mathrm{PhD}$ under her guidance. Further she provides consultations in the field of Intellectual Property to researchers, students and faculty members across seven faculty/Departments in Symbiosis International University for last 5 years. She has published several research papers on contemporary topics of Intellectual Property Rights and International Taxation. She has conducted invited sessions and symposiums during her visit to Leibniz University at Hannover, Germany in 2011 and Chuo University at Tokyo Japan in 2015 respectively. Further she has conducted workshops in the field of Intellectual Property Rights and has keen interest in research and community outreach programmes.

\section{Publications:}

1. Gurpur Shashikala, Rautdesai Rupal (11/2014) Revisiting Legal Education for Human Development: Best Practices in South Asia. Procedia - Social and Behavioral Sciences, 157: 254-265 (ScienceDirect; ISSN: 1877-0428). (National)

2. Rautdesai Rupal (12/2014) Patents and Patentability Strategy in India: An Alert for Inventors. Symbiosis Contemporary Law Journal, 2(1): 97-115 (ISSN: 978-93-5143-018-6). (National)

3. Rautdesai Rupal, Ahmed Munnazzar (06/2014) Sustainable Development via Green Technology: A Patent Perspective. Online International Interdisciplinary Research Journal, 4: 233 241 (DOAJ; ISSN: 2249-9598). (National)

4. Rautdesai Rupal, Nandekar Ujwal (03/2017) Online Photographs in News: Copyright Perspective. Media Watch, 8(1): 133-140 (Scopus; ISSN: 2249-8818). International Scopus

5. Nitin Kondalwade Patil, Dr. Rupal Rautdesai, Dr. Shashikala Gurpur (06/2018) Paper On Law Reforms In The Income Tax Act 1961 In Relation To Marketing Intangibles (Advertisement, Marketing And Sales Promotion) IJER - Volume 9 Issue 3 ISSN:2229-6158. (National)

6. Nitin Kondalwade Patil, Dr. Rupal Rautdesai, Dr. Shashikala Gurpur (06/2018) Advertisement, Marketing And Promotion Expenses Amp' Brief Study Of Cost-Benefit Relations Pertaining To Amp Expenses In Indian Markets Vis- ̀̀-Vis Emerging Trends, IJER - Volume 9 Issue 3 ISSN: 2229-6158. (National)

7. Rupal Rautdesai, Ujwal Nandekar, Aditya Kedari, Yogesh Patil, $(05 / 2019)$ "Big data and privacy - A legal perspective and comparative study of United States and India" International Journal of Process Management and Benchmarking, ISSN online: 1741-816X ISSN print: 1460-6739 International Journal Scopus Indexed 